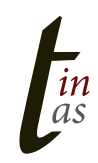

Tintas. Quaderni di letterature iberiche e iberoamericane, 10 (2021), pp. 57-67. ISSN: 2240-5437.

http://riviste.unimi.it/index.php/tintas

\title{
Lengua y cultura locales bajo el peso de la dependencia poscolonial: africanización de Recuerdos del abuelo Bayebé y otros relatos bubis de Justo Bolekia Boleká
}

\author{
Droh Joel Arnauld KefFa \\ Universidad Felix Houphouët Boigny \\ jojokeffa@gmail.com
}

\section{INTRODUCCIón}

El problema del continente africano y la falta de reconocimiento de sus valores tradicionales resultan de la colonización occidental. Jacint Creus afirma que «la colonización impuso una especie de identidad en espera, en que cada guineano podía o no, demostrar su grado de civilización» ${ }^{1}$. Lo que evidencia el origen del malestar existencial del sujeto cultural poscolonial. En efecto, tras la historia de las expediciones civilizadoras y evangelizadoras europeas en tierras africanas, África fue la receptora forzada de las religiones, lenguas y culturas occidentales. La razón de semejante ideología colonial era la imposición del modelo hegemónico europeo en la sociedad africana. Es por ello que la empresa colonizadora se enfocaba en la "asimilación"2 de sus valores culturales y religiosos, considerados supremos y universales para dar validez a la acción colonial. No solo por medio de la imposición de sus valores culturales sino también con la idea de su expansión territorial en África.

Desde entonces, para conservar su supremacía cultural y mantener el orgullo del nacionalismo occidental, los colonizadores recurrían a otra táctica ideológica en su campaña de civilización del territorio africano. Se trataba de la "inferiorización" ${ }^{3}$ del sujeto colonizado y del aniquilamiento de su patrimonio cultural. Lo que demuestra que el verdadero propósito ideológico de la colonización occidental era convertir y dominar al africano para que asumiera su condición de esclavo. Por lo que la ideología colonial occidental le imponía, a base de opresión, el consumo de sus valores culturales, políticos, lingüísticos

\footnotetext{
${ }^{1}$ Creus, Jacint, «Oralidad y literatura en Guinea Ecuatorial», Palabras. Revista de la Cultura y de las Ideas/Fundación España Guinea Ecuatorial, 1 (2009), p. 63.

${ }^{2}$ https://www.ecured.cu/Asimilación_cultural (fecha de consulta: 23/04/2020).

${ }^{3}$ La “inferiorización”, según el sistema colonial español, estaba inspirada en la cultura política de la metrópoli, $y$, por tanto, mostraba un escaso respeto por la diversidad cultural, lingüística y étnica de las poblaciones locales. ÁlvarezChillida, Gonzalo y Nerín Gustau, «Introducción. Guinea Ecuatorial: el legado de la colonización española», Ayer, 109 (2018), p. 20.
} 
y religiosos. En efecto, cabe apuntar que esta situación evocada es la copia conforme en Guinea Ecuatorial, donde la colonización española ha dejado parecidas secuelas en este país, contribuyendo al derrumbamiento de su patrimonio cultural y a la desestructuración de su tradición. Como consecuencia de ello, el sujeto poscolonial guineoecuatoriano ha sido despersonalizado. Navega en el contexto poscolonial entre dos culturas diferentes y a menudo antagónicas. Ndongo-Bidyogo al respecto subraya que:

Guinea es un país a la vez hispánico y africano, y en esa identidad simbiótica radica su originalidad, su esencia y la garantía de su autonomía. Al fundirse los valores de la cultura adquirida, los hispánicos, con los valores de la cultura heredada, los bantúes [...]. Hay guineanos que escriben, que pintan, que esculpen; que trabajan, en definitiva, desde su perspectiva Hispanoafricana, para dotar a su país de ese dinamismo sin el cual el progreso sería imposible ${ }^{4}$.

El autor desarrolla dos aspectos culturales fundamentales. Primero, enfatiza la fragmentación identitaria del sujeto cultural poscolonial, a caballo entre su tradición y la cultura hispánica, después afirma que el progreso nacional guineoecuatoriano pasa por la creación y la difusión literaria de las realidades socioculturales de su país. Esa unión entre lo social y lo tradicional que se nutren de la literatura, esto es, de la escritura como medio de existencia y de resistencia, es lo que se destaca en la introducción de la Antología de la literatura guineana:

La literatura se justifica, sobre todo, porque contiene las ideas básicas de una sociedad, las expresas y las ocultas, las concretas y las abstractas, las realizadas y las frustradas; razón por la cual habría que responder a interrogantes tales como la significación práctica de una obra literaria, su necesidad y su función social [...]. Para el africano, la literatura es necesaria, independientemente de su valor estético, pues a ella ha sido trasvasada toda la significación de las antiguas leyendas, que reflejaban una porción de la experiencia concreta y cotidiana de nuestros pueblos 5 .

De hecho, favorecidos por el contexto poscolonial que supone independencia y libertad de expresión, los autores guineoecuatorianos se sirven de la literatura. Según ellos, es un medio de expresión y conservación de la oralidad africana dentro de la escritura. Su objetivo es dar vitalidad a su patrimonio cultural que fue pisoteado durante la colonización española y reafirmar su "africanidad". No obstante, a esto hay que añadir que no solo se limitarán al sostenido esfuerzo de exaltación de lo africano, como evoca JosephDesiré Otabela, sino también «tratarán de enfocar en sus costumbres tradicionales su relación con la civilización moderna, [...] desarrollarán en sus textos temas relacionados con la historia de su país» ${ }^{7}$.

\footnotetext{
${ }^{4}$ Ndongo-Bidyogo, Donato, «Hispanidad», África 2000, 6 (1986), p. 3.

${ }^{5}$ Ndongo-Bidyogo, Donato, Antología de la literatura guineana, Madrid, Editora Nacional, 1984, p. 22.

6 El concepto de "africanidad" es una creación reciente de los movimientos culturalistas. En su introducción, Ndongo-Bidyogo lo define como un conjunto de los valores cosmogónicos que determinan al africano: Ndongo-Bidyogo, Donato y Faye Ngom, Mbare (ed.), Literatura de Guinea Ecuatorial. Antología, Madrid, Sial, 2000, p. 31.

${ }^{7}$ Otabela Mewolo, Joseph-Desiré, «Literatura de Guinea Ecuatorial. Sujeto cultural y dictadura: el personaje del abogado en Los poderes de la tempestad de Donato Ndongo-Bidyogo», Epos, 19 (2003), p. 121.
} 
De modo que la apuesta de la reconstrucción cultural y literaria aboque a una toma de conciencia del pueblo guineoecuatoriano de su situación de dominado. Lo cual se aprecia dentro de sus obras de expresión española, en las que resisten a través de la introducción de su lengua materna y de otros elementos de su cosmovisión tradicional. Es para ellos una estrategia de resistencia a las normas estructurales de la escritura occidental cuyo fin es dar reconocimiento a sus valores tradicionales. Es, pues, este mismo anhelo de independencia de los valores ancestrales guineoecuatorianos que se refleja en Recuerdos del abuelo Bayebé $y$ otros relatos bubis ${ }^{8}$ de Justo Bolekia Boleká. En ello, el autor lanza una mirada hacia el pasado y el presente del guineano. José Ramón Trujillo a este próposito escribe:

El presente exige volver a contar el pasado, reconstruirlo, emplearlo como molde de las nuevas acciones colectivas. Mientras tanto, el pasado permite comprender lo que sucede en el presente, permite distinguir los brotes de futuro, que apuntan en una dirección y no en otra, en el extremo de una rama cuya savia fluye desde las profundidades remotas?

Es decir que en cada relato Justo expone los retos de supervivencia a los que la lengua y las tradiciones orales bubi se enfrentan bajo la dominación cultural española. Su ambición es «invitarles a ser testigos de la confrontación entre mi endogeneidad y mi exogeneidad, o entre mi bubinidad y mi afrohispanidad mantenidas desde mi espacio diaspórico» ${ }^{10}$. De esta forma, lucha contra la dependencia poscolonial española, muy inquisitiva, en la que su personalidad está imbricada. Lo cual justifica el concepto de hibridez que se desprende de sus relatos, donde hace explícito el problema sociolingüístico y cultural del guineoecuatoriano poscolonial.

Nuestro trabajo consistirá en leer la obra de este autor según un enfoque poscolonial. Desde esta perspectiva estudiaremos las estrategias tradicionales utilizadas por este autor para dar un matiz africano a su obra. Además de ello, abordaremos el proceso de la autodeterminación cultural como respuesta al trauma colonial español.

\section{EL PROCESO DE “AFRICANIZACIÓN"11 DE LA OBRA ECUATOGUINEANA DE EXPRESIÓN ESPAÑOLA}

La colonización de Guinea Ecuatorial ha planteado muchos problemas en la sociedad guineoecuatoriana. Entre ellos, el problema de la búsqueda de identidad cultural africana. Por lo tanto, la época poscolonial sirve de marco a los intelectuales guineoecuatorianos para dar validez a su herencia africana. De hecho, su dimensión literaria en dicho contexto asume una función sociocultural y reivindicativa.

En efecto, es interesante apuntar que estos autores divulgan a través de sus producciones narrativas conocimientos tradicionales de su etnia y ciertas constructivas críticas sobre temas sociohistóricos para el progreso de Guinea Ecuatorial. Lo que coincide justamente

\footnotetext{
${ }^{8}$ Bolekia Boleká, Justo, Recuerdos del abuelo Bayebé y otros relatos bubis, Madrid, Sial Pigmalión, 2014.

9 Trujillo Ramón, José, «Estrategias narrativas para recuperar la memoria histórica en un contexto poscolonial», en Bolekia Boleká, Justo, Recuerdos del abuelo Bayebé y otros relatos bubis, Madrid, Sial Pigamalión, 2014, p. 7.

${ }^{10}$ Bolekia Boleká, Justo, «Exilio, lengua e identidad», en Lairys, Francoise Dubosquet, y Valcárcel, Carmen (ed.), Memoria(s) en transición. Voces y miradas sobre la Transición española, Madrid, Visor Libros, 2018, pp. 14-15.

${ }^{11}$ Es una estrategia que consiste en subvertir la escritura narrativa de expresión española con la oralidad.
} 
con la afirmación de Rizo al declarar que «el destino histórico de Guinea Ecuatorial va unido necesariamente a la Africanidad y a la Hispanidad» ${ }^{12}$. Según la autora, la comprensión de la literatura oral guineoecuatoriana reside no solo en su pasado colonial sino también en su condición hispánica, aspectos que fortalecen la doble identidad de su literatura. Ngom Mbare subraya lo siguiente:

La literatura africana escrita en español nace del encuentro de dos tradiciones culturales, la primera, negro-africana y ágrafa [...] y tiene normas expresivas y estéticas más flexibles y pragmáticas. En cuanto a la segunda, europea, importada e impuesta, se basa en la escritura y sus normas rígidas ${ }^{13}$.

Como vemos, la literatura guineoecuatoriana es híbrida. Su hibridez es una estrategia subversiva que permite a los autores guineoecuatorianos defenderse de la imposición de los valores culturales occidentales. Homi Bhabha da cuenta de los fines de la hibridización que, según él, implica una "subversión" de la autoridad colonial:

If the effect of colonial power is seen to be the production of hybridization rather than the noisy command of colonialist authority or the silent repression of native traditions, then an important change of perspective occurs. The ambivalence at the source of traditional discourses on authority enables a form of subversion, founded on the undecidability that turns the discursive conditions of dominance into the grounds of intervention ${ }^{14}$.

La subversión se nutre de la "hibridez" para romper con las exigencias del discurso narrativo exclusivamente expresado en la lengua del colonizador. En este contexto, la oralidad es el elemento clave utilizado por estos autores para dar una textura africana a su narrativa de expresión castellana.

\subsection{LA TRANSGRESIÓN ESTILÍSTICA Y CREACIÓN DE UNA ESCRITURA SUBVERSIVA}

La obsesión identitaria de los autores guineoecuatorianos ha contaminado todos sus textos narrativos poscoloniales. Su dinámica ideológica es la de proveer el terreno de la reconquista de su herencia africana para descolonizarse de las estructuras culturales españolas alienantes. Recuerdos del abuelo bayebé y otros relatos bubis sirve para tales fines. En efecto, cabe decir que Bolekia Boleká demuestra en ello su diferencia cultural empleando a África como materia narrativa. Se sirve de la oralidad dentro de la escritura para liberarse de los códigos narrativos que consideran la escritura como una propiedad europea. Ahora bien, Edward Said nos advierte de que:

La historia de la cultura no es otra que la historia de préstamos culturales. Las culturas no son impermeables; así como la ciencia occidental ha tomado cosas de los árabes, ellos las tomaron de los indios y los griegos. La cultura no es cuestión de propiedad, de tomar y prestar con garantías y avales, sino más bien de apropiaciones, experiencias comunes, e interdependencias de toda

${ }^{12}$ Rizo, Elisa, «La tradición en el teatro ecuatoguineano», Palabras. Revista de la Cultura y de las Ideas/ Fundación España Guinea Ecuatorial, 1 (2009), p. 151.

${ }^{13}$ Faye Ngom, Mbare, «Literatura africana de expresión española», Cuadernos, 3 (2003), p. 1. https:// www.guinea-ecuatorial.net/inicio.asp?cd=ni2564 (fecha de consulta : 23/04/2020).

${ }^{14}$ Bhabha, Homi, The location of culture, Nueva York, Routledge, 1994, p. 112. 
clase entre diferentes culturas ${ }^{15}$.

Desde entonces, la subversión literaria de este autor, hecha a base de insertar la "oralidad" dentro de la "escritura", evita la muerte de su historia cultural, de todo aquello que le define como bubi. Quiere así, dar a conocer su independencia lingüística, literaria y cultural. Lo cual explica el uso del bubi como instrumento de resistencia a la lengua del colonizador. Citamos esta muestra a título de ejemplo:

Yé béatta $m$ bë puerió böierí ö Bösöpé-Marcelo Bolekia Riokaló (lë sibötyíla sö Bösóngö); a sërélo èsuba ö wéá wásamöóte ö ruáá rué 2013; muè në'i ò léera balaáari, o sa bóhMma.

A mi padre, Bösöpé-Marcelo Bolekia Riokaló alias Bösóngö, fallecido el martes 31 de diciembre de 2013, de quien aprendí el dominio del silencio ${ }^{16}$.

El autor homenajea a su padre fallecido en su propia lengua. Dado el desconocimiento de esta lengua por el lector español, se reproduce también una versión en castellano. Su intención es enseñarle su lengua materna. Por ello la pone en primer lugar, para afianzar sus raíces ancestrales y su estilo narrativo. El segundo texto, traducido al español, le sirve para desligarse del rigor del pensamiento español. Esto demuestra que la esencia cultural de este autor se ha construido a base de dos modelos iniciáticos: el bubi y el español como lengua impuesta. Desde entonces, Bolekia Boleká emplea este material narrativo tradicional para desobedecer a la pureza de la escritura occidental. Afirma así su libertad cultural como un intelectual poscolonial.

La otra estrategia ideológica de subversión literaria se observa con los nombres bubi. En efecto, como lingüista ${ }^{17}$ y defensor de su tradición, Justo etiqueta a los personajes de sus relatos con nombres africanos. Esto pone de manifiesto su pertenencia étnica y su diferencia racial frente al colonizador. Tomando en consideración los relatos "Secreto del lenguaje", "Recuerdos del abuelo bayebé" y "Los mensajeros de Moka", citamos algunos de estos nombres bubi: «Bulawésa, Reha» (p. 31), «botúkku» (p. 33), «botyowéria» (p. 50), «rade, Sijeri», «Riokoréria, ndong Ensemunga» (pp. 56-57). Esto significa que Justo no ha perdido su amor por sus raíces ancestrales. Su manejo lingüístico le permite conservar su lengua en el cuerpo de la escritura. Su objetivo es evitar que se muera con el olvido o por falta de práctica. Ya que, desde su espacio diaspórico, el autor está privado de su utilización ante el español que, en cambio, habla con frecuencia. También, es bueno decirlo, el autor tiene miedo de que desaparezca su lengua silenciada, por lo que, la hace emerger para facilitar su reconexión con su espacio simbiótico. La lengua bubi tiene un valor sociológico y estético que sirve a africanizar el discurso narrativo español. Por eso, Justo dignifica el bubi con su código, su resonancia y estructura, para resaltar sus aportaciones lingüísticas y gramaticales. Esta técnica ideológica y narrativa tiene como propósito recrear una literatura oral bubi, dirigida a comunicarse con los miembros de su comunidad. De hecho, notamos que tiene también un alto grado de compromiso cultural, puesto que, su ideología literaria privilegia la defensa de su identidad africana y lucha contra la alienación de la lengua del colonizador. A esto se debe esta afirmación: «Hablar la lengua autóctona es estar en casa; mientras que hablar la del otro es salir a su encuentro» (p. 131).

\footnotetext{
${ }^{15}$ Said, Edward W, Cultura e Imperialismo, Barcelona, Anagrama,1993, p. 337.

${ }^{16}$ Justo Bolekia Boleká, Recuerdos del abuelo Bayebé y otros relatos bubis, p. 6. De aquí en adelante las referencias al libro de Justo Bolekia Boleká se insertarán entre paréntesis en las mismas citas.

${ }^{17}$ https://www.ecured.cu/Justo_Bolekia_Boleká (fecha de consulta: 23/03/2021).
} 
Esta muestra textual indica que el autor quiere ser él mismo y no otro. Lo que supone un sentimiento de pérdida de identidad y libertad del guineoecuatoriano al hablar la lengua del colonizador, en la medida en que implica sumisión, frustración y dominación. Bolekia Boleká, pues, valora su lengua materna para autodefinirse y alejarse de la opresión lingüística española.

A este efecto, es interesante subrayar que en su proyecto de africanización de sus relatos el autor recurre a la memoria. Es un mecanismo ideológico y tradicional que le permite conservar y reconstruir los hechos del pasado colonial español dentro de la escritura. Para que las generaciones futuras tengan un legado cultural lleno de verdades históricas. Así pues, la memoria histórica se convierte en una fuente oral de resistencia contra los esquemas históricos y culturales occidentales: «Es difícil borrar la memoria, porque la escribimos sin papel, ni lápiz, sin pizarrín -añadió el nonagenario Tope-tope-. Desde que pasó aquello hemos perdido muchas cosas» (p. 100). De hecho, cabe decir que para impedir la pérdida de "muchas cosas" la memoria histórica sirve de mecanismo de retrospección y protección de la oralidad. El autor memoriza los hechos sociohistóricos de su país, los plasma en la escritura, para que no se olviden. Lo cual muestra que la memoria histórica es una alarma contra la muerte cultural e identitaria del sujeto cultural poscolonial. De modo que pueda evitar el aniquilamiento de su identidad guineoecuatoriana, el autor introduce en sus relatos la imagen de los objetos sagrados bubi. Los inmortaliza en la escritura para despertar un sentimiento de autodeterminación cultural en la conciencia del guineoecuatoriano, como se aprecia en el siguiente fragmento: «Con un instrumento ancestral llamado Botyutyu, y con el que antiguamente se transmitían los mensajes de un lugar a otro dentro del mismo poblado, o entre poblados distantes» (p. 98). A través de esta operación de reconstrucción genealógica, Bolekia Boleká evita el naufragio de su tradición ancestral y de las reliquias de linaje. Su actuación permite reivindicar la paternidad del nacionalismo guineoecuatoriano. Es una táctica de resistencia y de reapropiación de su patrimonio cultural bubi ante la dominación cultural española.

\section{EL SISTEMA DE REAPROPIACIÓN DE LOS VALORES ANCESTRALES BUBI}

La divulgación de los valores tradicionales en la narrativa poscolonial guineoecuatoriana traduce un fuerte deseo de reconocimiento identitario. Justo Bolekia Boleká entiende bien esta congoja identitaria, por lo que valoriza la herencia tradicional para huir de la influencia negativa de los valores culturales occidentales. A este respecto, el mismo autor subraya en El País lo siguiente:

En Guinea les decía un día a unos chavales esto: "Queramos o no, tal y como están las cosas en este país, nuestras culturas se van a transformar, no van a desaparecer, pero se van a adaptar a vuestras necesidades, porque vosotros estáis abrazando ya una cultura no africana" ${ }^{\prime 1}$.

Como líder guineoecuatoriano, el autor encuentra su punto de apoyo en sus raíces africanas y lo mismo exige de su pueblo para la liberación del patrimonio tradicional del

${ }^{18}$ Caballero, Chema, «Elhacedor depolémicas»,ElPaís, 28/10/2017, https://elpais.com/elpais/2017/10/28/ africa_no_es_un_pais/1509185832_627449.html (fecha de consulta: 23/03/2021). 
dogma de la colonización española. Es por medio de esta ideología tradicional, cuyas líneas generales se describen en su obra, que habla eficazmente de su bubinidad.

\subsection{VALORIZACIÓN DE LA TRADICIÓN Y LAS COSTUMBRES GUINEOECUATORIANAS}

La oralidad se configura dentro de la narrativa guineoecuatoriana a través de sus formas de transmisión. De esta manera, el autor restituye a su pueblo su historicidad y ancestralidad. En efecto, hay que decir que el mundo tradicional bubi abarca muchos códigos y mensajes culturales determinantes para el bienestar del sujeto cultural poscolonial. Y entre estos mensajes aparecen los presagios. Tienen gran significado en la comunidad bubi. $\mathrm{Su}$ interpretación adivinatoria es una práctica tradicional que permite intuir y prevenir los acontecimientos venideros. Que sean ellos malos o buenos. Como cuando el narrador describe la aparición de las lechuzas en el poblado:

(Los pájaros de los grandes ojos nunca se han concentrado en la iglesia. Va a suceder algo inevitable. Alguien nos va a dejar para reunirse con nuestros antepasados. No podemos evitarlo. Las lechuzas ya se irán. Volvamos a nuestras casas y esperemos. No podemos hacer nada). (p. 34)

En el mundo tradicional bubi las lechuzas no son de buen augurio. Simbolizan la desgracia o la muerte. Y cuando aparecen así, las consecuencias son muy desastrosas e irreparables. Con esta referencia a los presagios, Bolekia Boleká nos enseña algo sobre el lenguaje esotérico africano. Nos informa de que los presagios son una fuente oral de conocimiento metafísico cuya comprensión requiere a los ancianos por su sabiduría. Es por ello que el autor honora a los abuelos. Les representa como defensores y sabios dentro del sistema comunitario tradicional. Bolekia Boleká muestra que los abuelos tienen gran facilidad de conexión con los antepasados, lo cual les convierten en intermediarios entre el presente y el mundo del más allá. De ahí que nace su respecto y veneración dentro del círculo tradicional bubi, como observamos a partir de esta muestra textual: «-Tu eres los ojos del pueblo, tú lo ves todo -intervino otro abuelo- Si dices que no podemos hacer nada y que volvamos a nuestras casas, así lo haremos» (ibidem).

Los abuelos son venerados por los miembros de la tribu bubi porque asumen una función de consejeros y protectores del clan. Su presencia tiene también relevancia porque ofician rituales a los espíritus sagrados, resuelven los problemas a los que la tribu se enfrenta. En este caso, recurren a la libación como método ancestral para implorar la bendición de los antepasados, como se observa en el relato "El bötúkku y sastre 'arakata": «Con unas fibras secas de dátiles limpió su interior y lo llenó de vino de palma. Lo bebió y dejó un poco para hacer una libación nombrando a dioses y ancestros» (p. 113). La libación forma parte de la espiritualidad africana. Consiste en la adoración de los antepasados desde su mundo de lo invisible. De este modo se implora su bendición, protección y elevación, ya que poseen poderes místicos cuya fuerza viene de la naturaleza africana. De ahí que Justo Bolekia Boleká exalte la naturaleza en su obra. Porque la geografía africana forma parte de la tradición guineoecuatoriana. En ella perviven dioses ancestrales con poderes místicos, misteriosos y a veces peligrosos. Es este peligro que evoca el narrador en su arriesgado recorrido por la selva: «salí huyendo en la noche, perdiendo mi miedo a los habitantes de la oscuridad, o a las siluetas de los grandes árboles» (p. 44). Aludiendo a «los habitantes de la oscuridad», el autor se refiere a la brujería, que es una sinuosa práctica del mundo guineoecuatoriano. Al subrayar que es "de noche", Bolekia Boleká muestra que es un momento que causa miedo por temor a los brujos, ya que es durante este momento 
que las fuerzas místicas de la naturaleza africana se enfrentan. Es decir, las fuerzas del mal contra las del bien. Esta es la razón por la que hay que respetar no solo la naturaleza africana sino también las tradiciones ancestrales que componen el mundo africano.

Entre estas tradiciones ancestrales se encuentran los tabúes. En efecto, los tabúes son creencias sagradas africanas que reglamentan la cohabitación de los miembros de la sociedad bubi. De hecho, es necesario respetarlos porque así se evitan desgracias y ofensas a las divinidades ancestrales. Esta realidad en torno a los tabúes se destaca en "El secreto del lenguaje", donde la vieja del poblado, dando consejos a su hija, afirma: «Ningún hombre debe saltar tus piernas- Dijo bulazÉsa'a a su hija Rehá- Porque te quedarías embarazada» (p. 31). Los tabúes son una obligación en la comunidad bubi. Su infracción tiene consecuencias en la vida del desobediente. Es sin duda lo que justifica igualmente esta superstición africana observada en "Recuerdos del abuelo bayebé", donde se prohibe no contestar sin haber visto previamente a la persona, porque nunca se sabe: «Además, siempre nos dicen que si alguien te llama y no le ves es mejor no contestar hasta que le veas, incluso cuando reconoces la voz» (pp. 43-44). Esta observación muestra que el sistema tradicional bubi se compone de reglas que imponen obediencia y respeto a los valores tradicionales, algo que garantiza la armonía entre los miembros de la tribu bubi y la supervivencia de sus valores. Precisamente para perennizar estos valores ancestrales el autor valoriza la medicina africana a través de las plantas tradicionales. Muestra así que son remedios curativos y eficaces. Y que, por ejemplo, a través de los mejunjes ${ }^{19}$ que derivan de las cortezas de los árboles, el guineoecuatoriano cura sus enfermedades:

(Mi abuelo Bayebé sacó un cubilete de coco de un rincón de su cabaña, metió un poco de su mejunje, lo probó y me dio a probar. Y como me habían enseñado a obedecer siempre a los mayores fuesen o no de mi familia, cogí el cubilete de coco con la pócima dentro y lo tomé en pequeños sorbidos hasta que lo terminé). (ibidem)

Las plantas tradicionales son un precioso legado ancestral. Esta medicina protege al guineoecuatoriano contra la enfermedad, y eso, sin recurrir a la medicina moderna.

Por otra parte, es interesante notar que la obra de Justo Bolekia Boleká nos enseña también algo sobre el modo de ser y de vivir de la sociedad guineoecuatoriana, puesto que en su obra habla del tema de la ritualidad. Para él, cada rito o ceremonia tradicional obedece a la adopción de ciertos comportamientos por parte del guineano, según los acontecimientos. Como es el caso del ritual de la muerte en el poblado de "Santiago Baney", con el personaje de "cachito": "Después de tantos intentos científicos y paracientíficos, cachito, mi sobrino consorte, dejó este mundo para ir a reunirse con sus ancestros, según acostumbran a decir nuestros mayores» (p. 4). Según las costumbres guineoecuatorianas la muerte es simbólica: es un largo viaje en el que el difunto se reúne con los antepasados de su tribu. Sin embargo, cabe decir que no solo se encuentra cierto simbolismo en la muerte sino también en la danza. En efecto, la danza es una expresión artística tradicional. Su celebración acompaña un momento de goce o dolor, según las circunstancias ceremoniales. Lo que significa que la danza es un arte africano relevante dentro de las costumbres tradicionales bubi como vemos a continuación: «Delante de la casa consistorial se organizó todo para repartir los obsequios del gobernador. Los jóvenes ejecutaron

\footnotetext{
${ }^{19}$ Brebaje líquido o pastoso a base de ingredientes naturales que se usan en Guinea Ecuatorial para curar a los enfermos: http://etimologias.dechile.net/?mejunje (fecha de consulta: 23/03/2021).
} 
el baile de la guerra y las muchachas el katyá, o baile de pesca» (p. 104). El katya ${ }^{20}$ como baile tradicional forma parte del patrimonio cultural guineoecuatoriano. Este baile consiste en cantos de alegría y proezas a los héroes de la comunidad. Y junto con esta danza tradicional, el autor habla también de la caza. En efecto, la caza es una actividad cotidiana que ejerce el campesino guineoecuatoriano en su medio tradicional. Durante esta actividad tradicional, este, trepa a la palmera para recoger aceite, y mata a los animales del bosque para su alimentación, actividad que le permite mantener a su mujer y a sus hijos. El narrador subraya esta actividad en el siguiente fragmento: «Mañana tienes que venir con nosotros a la finca a cazar de día, a trepar a la palmera de aceite, a desbrozar, a...- decía Elëbbó cuando fue interrumpido por la risa del ambiente gobernador» (p. 119). La caza es fuente de subsistencia para el guineano. Sin embargo, hay que añadir que el bosque no solo asume esa función alimenticia, sino que también se convierte en un lugar donde los ritos ancestrales tienen lugar.

En efecto, según la costumbre bubi, los ritos ancestrales son ritos de paso para los hombres. Dichos ritos se definen como un acto de agradecimiento al espíritu protector por la vida de la comunidad. Es también una etapa de crecimiento a través de la que el niño llega a ser hombre y, por consiguiente, respetado por su tribu. Este proceso iniciático por el que pasa es la circuncisión. Reche nos aclara al respecto que:

La iniciación africana es un medio de integración, identificación, apertura a la vida social, proceso que conduce a la madurez y que coge al joven en su conducta, inteligencia, afectividad [...]. A pesar de ello, en muchas sociedades persisten y no solo juegan un papel importante, también nos ayudan descubrir una filosofía sobre el hombre y los valores que se quieren transmitir ${ }^{21}$.

La autora muestra que la circuncisión es una práctica tradicional que marca la entrada del joven en el mundo de las responsabilidades sociales. A partir de ahí, se entiende el motivo de su imposición al gobernador español a la hora de casarse con sihiri, la bella muchacha negra:

(Don Justino gritaba desesperadamente, pero nadie le escuchaba. El anciano dio unos cuantos golpecitos al miembro viril ya excesivamente erecto del iniciando. Lo cogió y con un golpe rápido y seco, abdujo el prepucio [...] se autoinspeccionó la región pélvica y no pudo evitar un fuerte alarido, como si le cortaran una parte de su cuerpo. Estaba circuncidado.) (pp. 121-122)

La circuncisión es un rito simbólico que concede madurez al guineoecuatoriano. De hecho, su imposición al gobernador español es una prueba efectiva de reconocimiento occidental hacia esta práctica.

Para afirmar este reconocimiento, Bolekia Boleká valoriza otro rito ancestral que es el rito de la desfloración. Este rito es sagrado y está destinado a las mujeres africanas en la sociedad bubi. Su objetivo es purificar a las chicas antes del matrimonio. Lo cual suele producirse con un anciano de la comunidad bubi. Podemos observarlo en esta muestra textual: «El pregonero se levantó y partió. Comprendió que Sómetyityi había realizado ya

\footnotetext{
${ }^{20}$ Es un baile tradicional de la comunidad bubi que tiende a celebrar un hito importante. www.asojea. de/cultura/ (fecha de consulta: 03/09/2020).

${ }^{21}$ Reche, Paquita, «Sabiduría africana, la educación como proceso educativo», Fundación Sur, 02 de septiembre de 2010, http://www.africafundacion.org/sabiduria-africana-la-iniciacion-como-procesoeducativo-por-paquita-reche-mnsa (fecha de consulta: 23/03/2021).
} 
el rito de la desfloración» (p. 111). El rito de la desfloración, obviamente, se caracteriza por la pérdida de la virginidad por parte de la joven y esta creencia ancestral sirve a limpiar a las mujeres de sus impurezas, de manera que alcancen la madurez. Para esto, tienen que ser preparadas y formadas espiritualmente según las enseñanzas tradicionales. Es por ello que su educación tradicional es importante. Porque no solo es un asunto personal o individual sino comunitario. Es decir, que son los miembros de la comunidad bubi los que dan las bases de la educación social, espiritual y tradicional a los jóvenes o a las mujeres en la sociedad africana. Bolekia Boleká recuerda la importancia de la educación tradicional:

\begin{abstract}
Ya formamos a nuestros hijos y nietos con nuestros ritos y cosas tradicionales; tenemos nuestra curandería y nuestro oratorio o róhia para curarnos; tenemos ríos donde lavar nuestros cuencos y prendas; y ya están nuestras madres y mujeres para formar a las chicas, porque de los chicos nos encargamos nosotros. (p. 112)
\end{abstract}

La educación tradicional es uno de los pilares del sistema tradicional guineoecuatoriano. Es un órgano de transmisión de los valores morales africanos como la obediencia, el respeto y la disciplina a los jóvenes, lo que supone que ellos tienen que obedecer y someterse a las normas tradicionales para una mejor convivencia comunitaria. Por ejemplo, el narrador del libro de Bolekia Boleká declara: «Además, en la cultura bubi un sobrino jamás agrede a un tío materno. Quien lo hace, tarde o temprano cae en desgracia. Es una sentencia de inevitable cumplimiento, incluso después de la muerte» (p. 50). Como vemos, la educación tradicional está para dar al guineoecuatoriano un comportamiento tradicional ejemplar, para que pueda aplicar estos valores de respeto y sumisión en su vida cotidiana. Esto demuestra que la sociedad tradicional bubi funciona según un manojo de leyes e interdicciones ancestrales que permiten la cohesión social y la supervivencia de los usos y costumbres del grupo étnico bubi.

\title{
4. ConClusión
}

Hemos visto que el proceso de africanización de la narrativa guineoecuatoriana de expresión española se basa en dos estrategias importantes. Se trata de la estrategia de subversión de los códigos estructurales de la narrativa escrita en español y la de la reapropiación de los valores tradicionales africanos. Cabe decir que estas dos estrategias han servido para enfrentarse a la dependencia lingüística y cultural españolas. Lo cual, en la obra de Justo Bolekia Boleká, muestra que el autor puede convertirse en el proveedor de una verdad tradicional transgresiva. Sobre todo por medio de su compromiso con los rasgos tradicionales guineoecuatorianos, ya que busca construir las bases de una literatura oral en lengua $b u b i$, amenazada con desaparecer bajo el peso enajenante de la lengua del colonizador. Por eso Bolekia Boleká se sirve de los elementos tradicionales narrativos para luchar contra dicha hibridez que sufre en su propia piel y que le hace invisible, a caballo entre dos culturas que engendran una personalidad identitaria no reconocida ni siquiera en este período poscolonial.

A partir de ahí, para superar su malestar existencial y cultural, la escritura se convierte en un argumento ideológico para reclamar su descolonización frente a la civilización española. Esto justifica su empeño en valorar en sus relatos el legado ancestral $b u b i$, cuyo próposito es recuperar los valores tradicionales guineoecuatorianos y marcar 
su alejamiento de la servidumbre cultural española. Pensamos que el desafío literario de la obra de Bolekia Boleká, quien pone su voz al servicio de los que no pudieron alzar las suyas, tiene dos objetivos: por un lado, revolucionar las mentalidades de las futuras generaciones guineoecuatorianas - para que no se dejen seducir ni atrapar por la cultura asimiladora española que es una forma de prolongación de la dominación colonial cuyo interés es expandir la idea de una superioridad occidental-, por otro, restituir al pueblo africano, y especialmente al guineoecuatoriano, su dignidad y su belleza, tanto en la literatura como en la vida. Esto demuestra que Justo Bolekia Boleká es un africanista comprometido con la causa nacional y cultural de su país, y su obra, como reflejo de su imaginación y de su saber, es el testimonio de sus vivencias desde su espacio diaspórico.

\section{REFERENCIAS BIBLIOGRÁFICAS}

Álvarez Chillida, Gonzalo y Nerín, Gustau, «Introducción. Guinea Ecuatorial: el legado de la colonización española», Ayer, 109 (2018), pp. 13-32.

Bhabha, Homi, The location of culture, Nueva York, Routledge, 1994.

Bolekia Boleká, Justo, Recuerdos del abuelo Bayebé y otros relatos bubis, Madrid, Sial Pigmalión, 2014.

—, «Exilio, lengua e identidad», en Lairys, Francoise Dubosquet y Valcárcel, Carmen (ed.), Memoria(s) en transición. Voces y miradas sobre la Transición española, Madrid, Visor Libros, 2018, pp. 1-18. https://www.academia.edu/43253199/Exilios_lenguas_e_identidad (fecha de consulta 23/03/2021).

Caballero, Chema, «Elhacedor de polémicas», El País, 28/10/2017. https://elpais.com/elpais/2017/10/28/ africa_no_es_un_pais/1509185832_627449.html (fecha de consulta: 23/03/2021).

Creus, Jacint, "Oralidad y literatura en Guinea Ecuatorial», Palabras. Revista de la Cultura y de las Ideas/Fundación España Guinea Ecuatorial, 1 (2009), pp. 61-72.

Faye Ngom, Mbare, «Literatura africana de expresión española», Cuadernos, 3 (2003), pp. 1-4. https:// www.guinea-ecuatorial.net/inicio.asp?cd=ni2564 (fecha de consulta: 23/04/2020).

Labrador Fernández, Jésus, Identidad e immigración. Un estudio cualitativo con inmigrantes peruanos en Madrid, Madrid, Comillas, 2001.

Otabela Mewolo, Joseph-Desiré, «Literatura de Guinea Ecuatorial. Sujeto cultural y dictadura: el personaje del abogado en "los poderes de la tempestad" de Donato Ndongo-Bidyogo», Epos, 19 (2003), pp. 119-128.

Reche, Paquita, «Sabiduría africana, la educación como proceso educativo», Fundación Sur, 02/09/2010. http://www.africafundacion.org/sabiduria-africana-la-iniciacion-como-proceso-educativo-porpaquita-reche-mnsa (fecha de consulta: 23/03/2021).

Ndongo-Bidyogo, Dontao, Antología de la literatura guineana, Madrid, Editora Nacional, 1984.

—, «Hispanidad», África 2000, 6 (1986), pp. 2-3.

Ndongo-Bidyogo, Donato y Faye Ngom, Mbare (ed.), Literatura de Guinea Ecuatorial. Antología, Madrid, Sial, 2000.

Trujillo Ramón, José, «Estrategias narrativas para recuperar la memoria histórica en un contexto poscolonial», en Bolekia Boleká, Justo, Recuerdos del abuelo Bayebé y otros relatos bubis, Sial Pigamalión, 2014, p. 7.

Rizo, Elisa, «La tradición en el teatro ecuatoguineano», Palabras. Revista de la Cultura y de las Ideas/ Fundación España Guinea Ecuatorial, 1 (2009), pp. 147-154. https://estudiosafrohispanicos.files. wordpress.com/2014/07/revista-palabras-1.pdf (fecha de consulta: 23/03/2021).

Said, Edward, Cultura e Imperialismo, Barcelona, Anagrama, 1993. 